Article

\title{
Is the Vocabulary Level of the Reading Section of the TOEFL Internet-Based Test Beyond the Lexical Level of Japanese Senior High School Students?
}

\author{
Masaya Kaneko \\ Tokyo Denki University \\ doi: http://dx.doi.org/10.7820/vli.v03.1.kaneko
}

\begin{abstract}
The main goal of the present study is to answer the question of whether the lexical level of the reading section of the TOEFL Internet-based Test (TOEFL iBT) is beyond the vocabulary level of Japanese senior high school graduates. The lexical level was measured in terms of text coverage. The present study builds upon Chujo and Oghigian's study. The notable difference in methodology compared to earlier text coverage studies on the TOEFL is an examination of real past TOEFL iBTs. Two objectives are explored in the present study. First, this study aims to examine how well a vocabulary of 3,000 word families, which is the lexical size target for Japanese high school graduates set by the Ministry of Education, Culture, Sports, Science, and Technology, enables students to comprehend reading passages in the TOEFL iBT. Second, it estimates a vocabulary size required to reach $95 \%$ and $98 \%$ coverage of these passages. Results showed that the most frequent 3,000 word families plus proper nouns as well as words that are defined in context yielded an average text coverage of $88.5 \%$ and that 6,000 word families plus proper nouns and defined words accounted for $95 \%$ of the text, and around 10,000 word families $98 \%$. The findings suggest that Japanese high school graduates with a vocabulary of 3,000 word families would be expected to comprehend nearly $50 \%$ of reading passages in the TOEFL iBT and that learning a vocabulary beyond the 10,000-word frequency level may not be necessary unless $98 \%$ or more text coverage is required.
\end{abstract}

\section{Background}

On April 8, 2013 the education reform panel of the ruling Liberal Democratic Party of Japan suggested that the TOEFL Internet-based Test (TOEFL iBT) replace the National Center Test, which has been used for admission to all national, public, and 520 private universities in Japan (as of 2013). The proposal has provoked widespread criticism. One of the main objections to the adoption of the TOEFL iBT stems from arguments that a vocabulary beyond the 10,000-word frequency level is required to comprehend passages in the TOEFL and that the lexical level of the TOEFL therefore surpasses the level expected of Japanese senior high school graduates. In a newspaper article appearing in the Asahi Shimbun (Anonymous, 2013), Erikawa claims that the TOEFL requires a vocabulary beyond 
the 10,000-word frequency level. Sato (2013) maintains that a 15,000-30,000-wordfrequency-level vocabulary is needed for the TOEFL.

Past L2-reading research investigating the effect of the percentage of known words in discourse on comprehension suggests that achieving 95\% (Laufer, 1989) or 98\% (Hu \& Nation, 2000; Laufer \& Ravenhorst-Kalovski, 2010; Schmitt, Jiang, \& Grabe, 2011) coverage allows readers to gain adequate comprehension. Findings from several text coverage studies on the TOEFL partially support claims made by Erikawa and Sato.

Hirai (2000) examined six reading passages from an unofficial TOEFL preparation book. The vocabulary level was measured using the General Service List (GSL) (West, 1953) and the University Word List (UWL) (Xue \& Nation, 1984). She found that the 2,800 word families on the two lists provided an average coverage of $86.6 \%$ and that proper nouns made up around $2 \%$ of the texts. Hirai concluded that learning low-frequency vocabulary is necessary to prepare for the TOEFL, because it constituted more than $10 \%$ of the text.

Mizumoto (2006) compiled a one-million-word TOEFL corpus consisting of various sources including both official TOEFL practice tests and unofficial test preparation materials. The lexical level was calculated using the Japan Association of College English Teachers (JACET) 8000 word list (Ishikawa et al., 2003). The JACET list is a lemma-based frequency list that contains 8,000 words plus 250 additional basic words. It was compiled using the British National Corpus (BNC) and many other materials that are specifically aimed at Japanese English as a Foreign Language (EFL) learners such as Japan-developed Eiken tests, National Center Tests, and English textbooks for junior and senior high school students approved by the Ministry of Education, Culture, Sports, Science, and Technology (MEXT). Thus, the list is tailored for the Japanese EFL learning environment. Mizumoto found that the most frequent 3,000 lemmas from the list made up $82.4 \%$ of the tokens in the TOEFL corpus and that its lexical level did not show a striking difference to the level of vocabulary in other genres of texts.

Chujo and Oghigian (2009) examined one official TOEFL iBT practice test, the version of the TOEFL administered in Japan since 2006. They concluded that with a vocabulary of the most frequent 4,000 word families on Nation's BNC 14,000 word lists (2006), an examinee would gain 95\% text coverage of the TOEFL iBT.

Although informative, these earlier studies have several limitations. First, except for Chujo and Oghigian's (2009) study, the samples analyzed were all based on the older version of the TOEFL. However, different versions of the TOEFL may employ different lexical levels, as Chujo and Oghigian (2009) point out. These researchers compared text coverage figures obtained from the older and the current versions of the TOEFL. They found that to reach 95\% text coverage, there was a difference of around 1,500 word families. They concluded that the TOEFL iBT may employ more high-frequency vocabulary than the older version although they acknowledged that their sample was quite small. Second, the frequency lists used in some of the earlier studies are limited in that they are too small to provide $95 \%$ (Laufer, 1989) or 98\% text coverage (Hu \& Nation, 2000; Laufer \& RavenhorstKalovski, 2010; Schmitt et al., 2011). The GSL (West, 1953) and the UWL (Xue \& 
Nation, 1984) are not sufficient for this purpose. Similarly, Mizumoto (2006) found that the JACET 8,000 list accounted for just $89.4 \%$ of his one-million-word TOEFL corpus. Third, several past studies of lexical levels of the TOEFL contained mixed sources. Test items for both receptive and productive knowledge were incorporated into one corpus (Chujo, 2004; Chujo \& Oghigian, 2009; Mizumoto, 2006). The past TOEFL except for the original paper-based test consisted of three sections: reading, listening, and writing. The TOEFL iBT adds a speaking section to these existing sections. Past studies employed a text coverage approach to examine the vocabulary level of all three (Chujo, 2004; Mizumoto, 2006) or four sections (Chujo \& Oghigian, 2009), which is a methodological flaw. If we want to determine the likelihood of success in the reading section of the TOEFL, only reading passages should be analyzed.

With these limitations in earlier text coverage studies on the TOEFL, earlier findings and their subsequent suggestions should be considered tentative.

\section{Aims}

The present study examines the vocabulary level of reading passages in the TOEFL iBT from the perspective of Japanese senior high school graduates. The notable difference in methodology compared to earlier text coverage studies on the TOEFL is an examination of real past TOEFL iBTs, which had not been available to the public before 2013. Earlier studies thus had to examine materials from either practice tests developed by the Educational Testing Service (ETS), the developer of the TOEFL test, or unofficial TOEFL preparation books. Therefore, the present study should provide a more accurate measurement of the vocabulary level of reading passages in the TOEFL $\mathrm{iBT}$.

\section{Sample}

The present study examined 15 reading passages from five past TOEFL iBTs (Educational Testing Service, 2013). Each test contains three reading passages. The total number of tokens in the passages was 10,624, with an average of 708 per passage.

No modifications were made to the original passages. Chujo and Oghigian (2009) deleted all proper nouns, but the present study retained proper nouns because past studies on text coverage suggested that the deletion of proper nouns affects the results of text coverage studies (Brown, 2010; Kaneko, 2013). Kaneko compared coverage figures obtained from the reading passages in the 2004 Tokyo University entrance examination, with proper nouns deleted, and those with proper nouns left in. It was found that the text with proper nouns removed yielded around $1 \%$ higher coverage than the text with proper nouns.

\section{Methods}

The reading passages were examined using RANGE (Heatley, Nation, \& Coxhead, 2002). The text coverage obtained through the most frequent 3,000 word 
families from Nation's (2006) BNC word family lists and the vocabulary size required to achieve $95 \%$ and $98 \%$ coverage were estimated.

\section{Results}

Table 1 depicts cumulative text coverage figures on each reading section of the five past TOEFL iBTs. The BNC 3,000 word families plus proper nouns yielded an average of $87.8 \%$ (standard deviation, $S D=2.8$ ) text coverage. To reach $95 \%$ text coverage, 6,000-7,000 word families were required. With regard to $98 \%$ text coverage, 12,000-13,000 word families were necessary.

If we consider words whose meaning is provided in the test, more accurate estimates will be achieved. This modification should be taken into consideration because definitions or pictures are provided for some words appearing in passages of the TOEFL iBT. For instance, a picture of a chipmunk is provided in Test 5. The definition of feudalism is given in Test 4. Readers do not need to know these words beforehand. Thus, those defined words should be considered to be known words. Table 2 shows revised cumulative text coverage figures taking into account those defined words. The most frequent 3,000 word families plus proper nouns and defined words yielded an average of $88.5 \%$ text coverage $(S D=2.4)$. An average of 6,000 word families were necessary to reach $95 \%$ text coverage $(S D=0.8)$. This coverage may allow readers to gain a comprehension of $60.5 \%$ according to the estimates made by Schmitt, Jiang, and Grabe (2011). Converting this comprehension figure into a score on the TOEFL iBT, students with knowledge of 6,000 word families would be estimated to achieve a score of 18 out of 30 points in the reading section. To reach 98\% text coverage, around 10,000 word families were required.

Table 1. Cumulative Text Coverage Figures on the Reading Section from five Past TOEFL iBTs by Nation's BNC Lists

\begin{tabular}{lcccccc}
\hline Frequency band & Test 1 & Test 2 & Test 3 & Test 4 & Test 5 & Mean \\
\hline Proper nouns & 2 & 2.2 & 1.6 & 1.1 & 1.2 & 1.6 \\
1,000 & 72.9 & 67.5 & 78.2 & 72.9 & 71.9 & 72.7 \\
2,000 & 83.8 & 80 & 87.6 & 84.5 & 81.3 & 83.4 \\
3,000 & 88.2 & 83.9 & 91.2 & 89.4 & 86 & 87.8 \\
4,000 & 91.9 & 87.9 & 92.5 & 92.1 & 89.6 & 90.8 \\
5,000 & 94.9 & 91.3 & 94 & 93.9 & 91.3 & 93.1 \\
6,000 & 95.6 & 92.6 & 94.8 & 95.3 & 93.6 & 94.4 \\
7,000 & 96.2 & 94 & 95.7 & 96.1 & 94.6 & 95.3 \\
8,000 & 97.1 & 95 & 96.4 & 97.3 & 95.2 & 96.2 \\
9,000 & 97.5 & 95.9 & 96.7 & 97.7 & 95.4 & 96.6 \\
10,000 & 97.9 & 96.6 & 97.4 & 98.1 & 95.6 & 97.1 \\
11,000 & 98.2 & 96.9 & 97.8 & 98.2 & 95.6 & 97.3 \\
12,000 & 98.4 & 97.2 & 98.2 & 98.5 & 95.7 & 97.6 \\
13,000 & 98.7 & 98.2 & 98.4 & 98.8 & 96 & 98 \\
14,000 & 98.8 & 98.7 & 98.9 & 99.1 & 96.7 & 98.4 \\
Not in the lists & 99.9 & 100 & 100 & 99.9 & 99.9 & 99.9 \\
\hline
\end{tabular}

Note. Totals of percentages are not $100 \%$ because of rounding. 
Table 2. Cumulative Text Coverage Figures on the Reading Section from five Past TOEFL iBTs by Nation's BNC Lists, Defined Words Included

\begin{tabular}{lccrrrr}
\hline Frequency band & Test 1 & Test 2 & Test 3 & Test 4 & Test 5 & Mean \\
\hline DWs + PNs & 2.3 & 3.2 & 1.8 & 1.5 & 2.9 & 2.3 \\
1,000 & 73.1 & 68.5 & 78.4 & 73.2 & 73.7 & 73.4 \\
2,000 & 84.1 & 81 & 87.8 & 84.8 & 83.1 & 84.2 \\
3,000 & 88.5 & 84.9 & 91.4 & 89.7 & 87.7 & 88.5 \\
4,000 & 92.2 & 88.9 & 92.8 & 92.4 & 91.3 & 91.5 \\
5,000 & 95.2 & 92.3 & 94.2 & 94.1 & 93.1 & 93.8 \\
6,000 & 95.8 & 93.6 & 95 & 95.5 & 95.4 & 95 \\
7,000 & 96.4 & 95 & 95.9 & 96.4 & 96.3 & 96 \\
8,000 & 97.3 & 96 & 96.6 & 97.6 & 96.9 & 96.9 \\
9,000 & 97.7 & 96.9 & 96.9 & 97.9 & 97.1 & 97.3 \\
10,000 & 98 & 97.6 & 97.6 & 98.2 & 97.4 & 97.8 \\
11,000 & 98.4 & 97.9 & 97.9 & 98.2 & 97.4 & 97.9 \\
12,000 & 98.6 & 98.2 & 98.3 & 98.5 & 97.5 & 98.2 \\
13,000 & 98.8 & 98.9 & 98.6 & 98.8 & 97.7 & 98.6 \\
14,000 & 98.9 & 99 & 99 & 99.2 & 98.3 & 98.9 \\
Not in the lists & 99.9 & 100 & 100 & 100 & 99.9 & 99.9 \\
\hline
\end{tabular}

Note. Totals of percentages are not 100 because of rounding.

$\mathrm{DWs}=$ defined words; PNs = proper nouns.

Schmitt et al. (2011) suggest that this coverage figure would allow readers to gain $68.3 \%$ comprehension, or 20 out of 30 possible points in the reading section of the TOEFL.

\section{Conclusions}

To summarize, if we add proper nouns and words that are defined in the passages to the counts of the most frequent 3,000 word families, readers would be able to gain $88.5 \%$ text coverage of reading passages on the TOEFL iBT. Assuming that senior high school graduates acquire a vocabulary of 3,000 word families, which is the lexical size target set by the current Course of Study guidelines (MEXT, 2009), then students would be estimated to achieve nearly $50 \%$ comprehension in the TOEFL iBT according to the estimates made in a recent large-scale lexical and reading comprehension study (Schmitt et al., 2011). If students acquire 3,000 additional word families, they would be able to reach $95 \%$ text coverage $(S D=$ 0.8). If students wish to enroll in an English-speaking university, 95-96\% text coverage will be the first lexical-coverage target because this coverage figure may enable test takers to gain a comprehension of 60-63\% as suggested by Schmitt et al. (2011). According to the official TOEFL iBT guide (Educational Testing Service, 2009), the average score for test takers who were applying for admission to Englishmedium colleges or universities as undergraduate students was 76 points $(63 \%)$. For instance, Temple University Japan, which is the only four-year English-speaking American ${ }^{1}$ university accredited by the MEXT, requires applicants to submit a score of 71 points $(59 \%)$ or more to be matriculated for the undergraduate course. 
In conclusion, the answer to the question of whether the lexical level of reading passages in the TOEFL $\mathrm{iBT}$ is beyond the vocabulary level of Japanese senior high school graduates depends on the desired comprehension level. If we assume that students would aspire to 45 points out of 120 in the TOEFL iBT, or $37.5 \%$, as proposed by the head of the ruling Liberal Democratic Party's education reform panel (Anonymous, 2013), then 3,000 word families would be sufficient. In contrast, if students aim to enroll in an English-speaking university, the ideal lexical size target would be beyond the vocabulary size goal proposed by the MEXT, because at least 3,000 additional word families would be required.

Lastly, the findings of the present study should be confirmed with a different methodology. Lexical level of texts can be measured in two ways: by examining the text coverage that different frequency bands yield, or by examining students on text comprehension and relating that to their vocabulary size. The present study took the first approach. Aizawa and Iso (2008) explored the vocabulary level of reading passages in the TOEFL employing the latter method. However, the limited number of subjects and short length of the materials they sampled do not allow us to reach any solid conclusion. Measuring students' comprehension on reading passages from real past TOEFL iBTs and relating these scores to their lexical knowledge needs to be done to confirm the results of the present study.

However, two findings in the present study seem to be clear. First, the TOEFL proposal made by the education reform panel might not be as senseless as has been claimed because the 3,000 word-family goal for high school students would allow test takers to gain nearly $50 \%$ comprehension of the reading section in the TOEFL iBT. Second, learning a vocabulary beyond the 10,000-word frequency level would not be necessary unless $98 \%$ or more text coverage is desired. Hopefully, the findings of the present study can provide new insights into the discussion on the use of TOEFL as part of university entrance examinations.

\section{Note}

1. The word "American" was unfortunately omitted from the original version of this paper (published Online First on March 15, 2014, page 5).

\section{References}

Aizawa, K., \& Iso, T. (2008). Identifying the minimum vocabulary size for academic reading. Annual Review of English Language Education in Japan, 19, 121-130.

Anonymous (2013, May 1). 大学入試に T O E F L [Adoption of the TOEFL as part of university entrance examinations]. Asahi Shimbun, p. 15.

Brown, D. (2010). An improper assumption? The treatment of proper nouns in text coverage counts. Reading in a Foreign Language, 22(2), 355-361.

Chujo, K. (2004). Measuring vocabulary levels of English textbooks and tests using a BNC lemmatized high frequency word list. In J. Nakamura, N. Inoue, \& T. Tabata (Eds.), English corpora under Japanese eyes (pp. 231-249).

Amsterdam: Rodopi. 
Chujo, K., \& Oghigian, K. (2009). How many words do you need to know to understand TOEIC, TOEFL and EIKEN? An examination of text coverage and high frequency vocabulary. The Journal of Asia TEFL, 6(2), 121-148.

Educational Testing Service. (2009). The official guide to the TOEFL test (3rd ed.). New York: McGraw-Hill.

Educational Testing Service. (2013). Official TOEFL iBT tests with audio (Vol. 1). New York: McGraw-Hill.

Heatley, A., Nation, I.S.P., \& Coxhead, A. (2002). RANGE and FREQUENCY programs. Retrieved from http://www.vuw.ac.nz/lals/staff/Paul_Nation

Hirai, A. (2000). An analysis of vocabulary used in STEP 1st and pre-1st grades, TOEFL, and TOEIC. 言語文化論集, 54, 1-16.

$\mathrm{Hu}$, M., \& Nation, I.S.P. (2000). Unknown vocabulary density and reading comprehension. Reading in a Foreign Language, 13(1), 403-430.

Ishikawa, S., Uemura, T., Kaneda, M., Shimizu, S., Sugimori, N., Tono, Y., ... Mochizuki, M. (2003). 大学英語教育学会基本語リスト [JACET list of 8000 basic words]. Tokyo: JACET.

Kaneko, M. (2013). Estimating the reading vocabulary-size goal required for the Tokyo University entrance examination. The Language Teacher, 37(4), 40-45.

Laufer, B. (1989). What percentage of text-lexis is essential for comprehension? In C. Lauren \& M. Nordman (Eds.), Special language: From humans thinking to thinking machines (pp. 316-323). Clevedon: Multilingual Matters.

Laufer, B., \& Ravenhorst-Kalovski, G.C. (2010). Lexical threshold revisited: Lexical text coverage, learners' vocabulary size and reading comprehension. Reading in a Foreign Language, 22(1), 15-30.

Ministry of Education, Culture, Sports, Science, and Technology (MEXT). (2009). 高等学校学習指導要領 [The course of study guidelines for upper secondary school]. Tokyo: Author.

Mizumoto, A. (2006). TOEFL 語彙の語彙レベル、真正性、特徵の検証 [Word levels, authenticity, and characteristics verification of the TOEFL vocabulary]. 言語文化学会論集, 27, 3-15.

Nation, I.S.P. (2006). How large a vocabulary is needed for reading and listening? The Canadian Modern Language Review, 63(1), 59-82. doi:10.3138/cmlr.63.1.59

Sato, M. (2013, May 31). 大学入試 T O E F L 導入への疑義 [Dispute over the adoption of the TOEFL as part of university entrance examinations]. 内外教育, 6250,1 .

Schmitt, N., Jiang, X., \& Grabe, W. (2011). The percentage of words known in a text and reading comprehension. The Modern Language Journal, 95, 26-43. doi:10.1111/j.1540-4781.2011.01146.x

West, M. (1953). A general service list of English words. London: Longman, Green and Co.

Xue, G., \& Nation, I.S.P. (1984). A university word list. Language Learning and Communication, 3(2), 215-229.

Vocabulary Learning and Instruction, 3 (1), 44-50. 